\title{
Identifying Knowledge Brokers in Enterprise Social Media
}

\author{
Mia Leppälä \\ Aalto University \\ mia.leppala@aalto.fi
}

\author{
J. Alberto Espinosa \\ Kogod School of Business \\ American University \\ alberto@american.edu
}

\begin{abstract}
Knowledge brokers act as a bridge between people and issues; they facilitate knowledge creation and sharing, and connect communities of practice. The extant literature has focused mostly on roles and network positions of knowledge brokers. This paper adds communicative actions to identifying these important actors. In the present study we develop and propose a method to identify knowledge brokering communication in an enterprise social media (ESM) platform. We posit that active knowledge brokers can be identified based on their generic social media communication. We use a large data set containing 124,015 messages among employees, and their network positions by social network analysis to identify knowledge brokers, and further analyze a sample of the communication content qualitatively. We argue that better understanding of the identification of knowledge brokering communication in a collaboration network can benefit employee assignments and help develop communication practices in ESM, leading to improved knowledge sharing and creation.
\end{abstract}

\section{Introduction}

A knowledge broker is an individual who connects information or creates new ways of using existing knowledge in an organization [10, 46, 48]. Knowledge brokering involves bringing people together, aggregating or creating new knowledge and exchanging ideas that can enable employees to perform their jobs better [21, 32]. Organizations today operate in complex global business environments. Virtual collaboration tools and practices are increasingly used to manage such globally dispersed organizations. To succeed, organizations need to recognize, adopt and effectively utilize the ever-increasing amount of knowledge available to them.
Many studies on knowledge brokers concentrate on explaining knowledge brokering roles based on interviews or survey data [47]. Our empirical data allows us to study knowledge brokering based on actual conversations. This brings a new approach to the research on knowledge brokering. Analyzing knowledge brokering communication helps organizations identify knowledge brokers in their networks and benefit from their operations. Mäkelä et al. [34] pointed out that it is important to acknowledge actors who share knowledge, as they have an important role in collaboration and coordination in dispersed organizations.

We explore how to identify knowledge brokers in a large virtual communication network emphasizing the communicative actions of such knowledge brokers in enterprise social media. Our first research question is: "How can knowledge brokers be identified in enterprise social media?" We focus on the communication practices that lead to knowledge brokering activities. This leads to our second research question: "What kinds of communicative actions do knowledge brokers use?" By communicative action we mean discussions that aim at mutual understanding. In the theory of communicative action, Habermas [20, page 5] argues that communicative action not only helps achieve understanding, but it also helps coordinate the goaldirected activities of different members, and promote their socialization. Members in communities of practice exchange a vast amount of information. Dennis et al. [13] refers to this exchange of information as "conveyance". However, they argue that members also need to engage in "convergence" communication to make sense of the information conveyed [13]. Without convergence the information has little utility. Further, taking into account Espinosa et al. [17] research findings that communication convergence is positively related to higher product quality, we believe that it is important to study this communication behavior more closely in knowledge brokering conversations. We argue that the communicative action of knowledge brokers leads to such convergence and mutual understanding." 
Knowledge brokers and knowledge brokering practices offer a useful lens to help us understand how organizations manage their operations using the knowledge-based resources available to them. A better understanding of knowledge brokering and the communicative actions of knowledge brokers provide organizations new opportunities to develop organizational communication and knowledge sharing and creation. While knowledge brokers will always play a useful role, we posit that they are particularly valuable when certain members of a network are in a position to bridge knowledge between otherwise unconnected, or partially connected members in a network. Such members are said to have high "betweenness" centrality [19]. Members with high betweenness centrality enjoy a position of prominence in networks because they are in a better position to broker, bridge and control relationships between members [4]. Our study contributes by exploring this perspective in the context of knowledge networks adding knowledge brokering communication to the discussions.

\section{Theoretical Background}

This paper looks at knowledge brokering through enterprise social media. The extant literature also refers to knowledge brokering as knowledge spanning, bridging and translating, among other terms [29, 34]. Boundary spanning $[29,34,44]$ is quite extensively studied area, but we distinguish the term knowledge brokering in this research. The main difference between the terms knowledge broker and boundary spanner is that boundary spanners are usually seen to operate between boundaries such as geographical distances or expertise differences [8, 34] whereas knowledge brokers in our study operate also within their own community of practice and with people who has similar knowledge base.

\subsection{Knowledge Brokering}

Knowledge brokering is important for organizations because it helps connect knowledge from various parts of the organization, which probably would not be connected otherwise, thus helping employees in organizational network perform their jobs better. Knowledge brokering involves bringing people together, as they know who knows whom and who knows what [25]. There is convincing evidence in transactive memory research that knowing who knows what $[26,31,42]$ and knowing where expertise resides in a group [18] helps group performance. Knowledge brokers also share ideas and information [21, 32]. According to Wenger [48, page 109] brokering is the "use of multi-membership to transfer some element of one practice into another". Knowledge brokering occurs as participants in any collective practice share understandings about what they are doing and what this means in real time, and knowledge is co-constructed by participants through socially shared "webs of belief" [6]. A knowledge broker is the individual who connects information or creates new ways of using existing knowledge $[10,46,48]$ across the network. Wenger [48, page 109] argued: "Brokers are able to make new connections across communities of practice, enable coordination, and - if they are good brokers - open new possibilities for meaning".

Knowledge brokers act as bridges between different communities of practice and facilitate interaction. Knowledge brokers also facilitate the transfer of knowledge among organizational units [38, 41]. The ability to develop relationships among colleagues is emphasized in virtual environments where physical connections are missing. Virtual knowledge brokers use technical systems that enable knowledge creation, connecting people from diverse communities of practice [46]. Because knowledge develops incrementally by integrating aspects of knowledge previously unconnected, knowledge brokers enable effective collaboration and knowledge creation in virtual environments [27, 41, 46]. Studies have shown how information and knowledge are bridged between researchers and healthcare industry [14, 28]. Cillo [10] showed that companies use internal knowledge brokers to absorb market knowledge. Knowledge brokers seem to act as relationship builders as they create knowledge by establishing new concepts and finding solutions to problems [32].

The extant research on knowledge brokering focuses mainly on innovation [10, 46] and highlights that knowledge brokers act as: a) enablers for innovation providing connection between various parties in the organization; and b) translators who take care that everyone knows what is discussed in the network. Several scholars have studied virtual knowledge brokers by treating the role of the knowledge broker as a third person who does not necessarily participate the collaborative task [21, 46]. In this paper, however, knowledge brokers are members in the operational groups working together and communicating to each other. Our study contributes to the research literature by incorporating the actual communicative actions of knowledge brokers in a virtual environment, thus informing how knowledge brokering operates in collaboration networks.

\subsection{Knowledge Creation}

It is generally assumed that the attainment of higher levels of knowledge is what will inevitably lead to 
higher levels of performance, output and productivity. This fuels the current interest with knowledge creation and knowledge management, particularly within management and organization studies [9]. Knowledge creation research is linked to research in knowledge management and knowledge sharing. These areas have been extensively studied since late 1990 's and early $21 \mathrm{st}$ century $[2,12,36]$. Leaning on the theories on knowledge management that view knowledge as a competitive advantage for an organization, knowledge creation studies have been striving to find answers to how such knowledge operates when people collaborate. Organizational knowledge creation is the process of making available and amplifying knowledge created by individuals as well as crystallizing and connecting it to an organization's knowledge system [35]. This approach highly resonates with today's organizations in which knowledge is core to the business. However, taking into consideration that it is actually people who do the sharing and creation of knowledge in organizations, the individual knowledge creation process alone does not answer the question of how knowledge develops in organizations [16]. Analyzing the actual communicative actions that knowledge brokers use provides more effective approach to understand the nuances of how knowledge evolves within a group.

\section{Data}

The focal organization of this case study is a global electronic consumer products manufacturer employing tens of thousands of people. The data consists of enterprise social media conversations of the employees during a period of 2 years and 8 months. The company adopted the social media tool (SocialCast, www.socialcast.com) to boost internal communications. Overall, the data set contains 32,902 message threads and 124,015 messages. In this study, active knowledge brokers are identified from the wider data set and the content analysis is focused on the communication threads in which the selected individuals have participated, covering an amount of 12,958 posts in total.

The first author has worked in the case organization and is therefore acquainted with the organizational environment in which the social media discussions are held. She is familiar with the processes and the technology used in the organizational communication and is familiar with the ESM tool used to communicate and gather data for the study. This data contained communication exchanges where employees openly discussed sensitive organizational issues. All data was anonymized to protect the privacy of the employees and the company specifics.

\section{Methodology}

We adopted mixed method [33] approach and we conducted the analyses in three stages. In the preanalysis stage, we identified the most probable knowledge brokers by the number of messages per each actor. We then further analyzed the data using social network analysis (SNA) methods and qualitative content analysis. We chose these methods to get a deeper understanding of knowledge brokers' communicative actions in the ESM. We provide further details of our analysis in the following sections.

The context of this study is enterprise social media (ESM) which enables knowledge sharing and provides an opportunity to explore the development of communication of knowledge brokers over time [24, page 2]. It is an open media internally, but not externally. Effective internal communication is the key to success in organizational knowledge sharing and collaboration, and it creates the conditions for organizations to access knowledge-based resources [3, $5,30]$. Internal knowledge creation benefits from the internet [15, 23], globalization [1, 23], and new technologies that enable individuals to work as a team in physically or organizationally dispersed locations $[22,40,49]$. The new technologies afford open communication [24] and knowledge brokers are capable to utilize this.

\subsection{Pre-analysis: Selecting the Active Knowledge Brokers}

The purpose of the pre-analysis was to scan the data and identify the actors who were more likely to act as knowledge brokers. The first criterion for this identification was the actor's social media activity. The most active knowledge brokers were determined to be the actors who are active both in opening new message threads as well as commenting on ongoing message threads. We conjectured that actors who opened conversations were interested in acquiring knowledge and finding answers to problems, and that actors who commented a lot acted as communication exchange facilitators [41].

The first stage in the identification of the knowledge brokers was analyzing the activity of each actor in the conversations. The conversations of actors in the data consisted of opening and commenting posts. First, we identified the opening posts and calculated the number of the opening posts per actor. Second, we counted the number of comments made by each actor. We further examined the activity of the knowledge brokers with the SNA concept of betweenness centrality [39].

Centrality is a measure of the prominence of actors in a network, but there are various measures of 
centrality. We use the concept of "betweenness centrality", which identifies which actors stand most between other actors. This is an important measure for our research, because a knowledge broker is precisely a member who sits in between other members bridging knowledge between actors. Betweenness centrality is computed by counting how many times an actor is in the shortest path between all other pairs of actors, relative to the total number of pairs in the network [19]. We used the number of messages as the respective edge weights of the communication network. Our analysis revealed that the number of posts and the betweenness centrality recognized the same actors to be the central in the organizational network. We identified 50 active knowledge brokers in the network. The betweenness centrality of opening messages of the identified 50 knowledge brokers ranges from 80,950 to $1,461,403$. Finally, we selected seven most active knowledge brokers from the 50 for further qualitative analysis. The chosen actors were most active both in opening the conversations and in commenting the posts of other actors. We describe the active knowledge broker identification process in more detail in the following chapter.

\subsection{Active Conversation Openers and Commenters}

We identified the most active users in two steps. First, we selected those who posted the most openings. Users who opened more conversations were sharing more information and searching for more answers. Also, actors who posted more opening comments were more interested in finding out solutions and wanted to share more information and knowledge [32]. Second, we selected the actors who sent the most comments as the actors who were most active in enabling conversations, and then followed their conversations in the internal social media.

In general, actors who posted the most openings also seemed to be most active posting comments. However, among the actors posting the most openings there were exceptions: actors who post hundreds of openings but only a few or no comments. We excluded actors who had no more than 100 messages of both opening and commenting posts. In order to be classified as a knowledge broker, the actor had to be active both in the number of opening and commenting posts. Finally, there were seven actors who were selected to represent the most active knowledge brokers in our sample, which we used to analyze their communication in more depth. The number of posts made by these seven actors was 12,958 , which is a substantial amount.

After selecting the most active knowledge brokers, we moved on to analyze the actual contents of the social media conversations. Our focus turned into discovering how these active knowledge brokers acted communicatively in the ESM. In the next section we discuss the findings of our qualitative content analysis.

\subsection{Qualitative Analysis}

In the third stage of the analysis we conducted a qualitative content analysis of the conversations in which the seven most active knowledge brokers had partaken. There were 12,958 posts including both opening posts $(1,744)$ and commenting posts $(11,214)$ of the seven selected actors. We analyzed the posts by reading each of them and then coding the respective data based on the actions that we identified in the conversations. We further analyzed the text data by searching for similarities in the conversations. Finally, we identified the main actions of the knowledge brokers as: connecting, exploring and interacting.

In the following section we elaborate the communicative actions of knowledge brokers through examples. The examples are excerpts of the conversations of the selected knowledge brokers. We illustrate each main action (connecting, exploring and interacting) with a data excerpt and an analytic explanation of the knowledge brokering actions. These examples help us illustrate how the knowledge brokers actually communicate in the social media conversations.

\section{Findings}

\subsection{Knowledge Broker Connecting People and Issues}

Collaboration in dispersed organizations is generally time-consuming and vulnerable for misunderstandings [17]. In dislocated settings, where employees work from multiple geographical places, those who know what other employees are capable of, and who are able to connect employees with knowledge needs and resources have the opportunity to increase collaboration $[25,29$, 37, 43]. Connecting actors and issues is one of the actions of a knowledge broker. In our first example one actor (Actor115) is actively adding several other actors to the conversation and pointing out where they could help in the on-going discussion. Tables 1 and 2 demonstrate situations in which the knowledge broker acts as a bridge [29, 32]. Table 1 contains an extract of conversations where the knowledge broker is connecting people. The grey shading in the table link the data excerpt and the designated analytic explanation. 
Table 1. Knowledge broker connecting

\begin{tabular}{|c|c|}
\hline Data excerpt & Explanation \\
\hline $\begin{array}{l}\text { Actor115: Hmm... From pure trialing } \\
\text { point of view, it's more effective to be } \\
\text { evil and simply drop all proto } \\
\text { owners. Most of us have production } \\
\text { devices (at least out of Proto X } \\
\text { users), and it is a fact that precious } \\
\text { time of key stakeholders has been } \\
\text { wasted for false alarms caused by } \\
\text { early proto hardware. But on the } \\
\text { other hand, I do understand how it is } \\
\text { completely against our "everybody } \\
\text { invited to help" ethos. Bad for the } \\
\text { overall spirit. @Actor598 is the } \\
\text { business owner here, so he has the } \\
\text { power to reverse the decision if he } \\
\text { so chooses. @Actor244 and } \\
\text { @Actor1258 flagged as well. For this } \\
\text { round, I'll send the update } \\
\text { instructions to proto owners as well, } \\
\text { pointing to this InternalSocialMedia } \\
\text { post, and highlighting that they } \\
\text { should indicate having prototype } \\
\text { hardware in their R\&D Intra site } \\
\text { problem reports etc. }\end{array}$ & $\begin{array}{l}\mathrm{KB}=\text { Actor } 115 \\
\text { In the excerpt } \\
\text { Actor115 is } \\
\text { referring to actors } \\
598,244 \text { and } \\
1258 \text { to being } \\
\text { possible } \\
\text { resources of } \\
\text { information for } \\
\text { the matter in } \\
\text { question. He links } \\
\text { these actors into } \\
\text { the message } \\
\text { thread using the } \\
\text { social media } \\
\text { feature where a } \\
\text { new user can be } \\
\text { linked by using a } \\
\text { command } \\
\text { '@user_name'. }\end{array}$ \\
\hline $\begin{array}{l}\text { Actor115: Talk with -@actor1258 } \\
\text { about your wishes for "Company } \\
\text { Events". If feasible, these will be } \\
\text { arranged with local customs in mind. } \\
\text { About badges, ask -@actor613. }\end{array}$ & $\begin{array}{l}\text { Actor } 115 \text { is } \\
\text { pinpointing two } \\
\text { actors } 1258 \text { and } \\
613 \text { because he } \\
\text { has indicated that } \\
\text { those actors } \\
\text { know what is } \\
\text { looked for. }\end{array}$ \\
\hline $\begin{array}{l}\text { Actor115: Might be overkill to set it } \\
\text { up, considering the backend etc. Ask } \\
\text {-@actor } 2751 \text {. If the schedule is tight, } \\
\text { you probably want to use something } \\
\text { different. }\end{array}$ & $\begin{array}{l}\text { Actor } 115 \text { is } \\
\text { suggesting to } \\
\text { contact actor } 2751 \\
\text { as he/she has } \\
\text { better knowledge } \\
\text { for decision } \\
\text { making. }\end{array}$ \\
\hline
\end{tabular}

Knowledge brokers help bridge communities of practice and connect people and information [10, 46, 48]. Table 2 shows an extract from the data, highlighting a situation in which the knowledge broker (Actor733) shares information from one community of practice to another.

\section{Table 2. Knowledge broker sharing information}

\begin{tabular}{ll}
\hline Data excerpt & Explanation \\
\hline $\begin{array}{l}\text { Actor67: when can we start } \\
\text { using pre-commercial }\end{array}$ & $\mathrm{KB}=$ Actor733 \\
versions of that & \\
(ProductM)? & \\
\hline
\end{tabular}

\begin{tabular}{|c|c|}
\hline $\begin{array}{l}\text { Actor733: some people are } \\
\text { using them already but still } \\
\text { too few... I guess my related } \\
\text { question is: can we tools to } \\
\text { flash ProductM on existing } \\
\text { PlatformW devices? like that } \\
\text { we would reduce the risks of } \\
\text { leakages big time but we } \\
\text { would have people using } \\
\text { and getting familiar with } \\
\text { ProductM.. }\end{array}$ & $\begin{array}{l}\text { Actor733 is sharing } \\
\text { information that is known } \\
\text { only by persons not involved } \\
\text { in this message thread: } \\
\text { product availability and } \\
\text { security concerns related to } \\
\text { early availability. }\end{array}$ \\
\hline $\begin{array}{l}\text { Actor733: @actor } 14435 \text { yes } \\
\text { I know I'm now in the same } \\
\text { room with them ;) I just } \\
\text { spoke to Actor } 166 \text { and told } \\
\text { him about the idea of getting } \\
\text { SW flashing capabilities in } \\
\text { Taipei. Otherwise they could } \\
\text { use your facility. Meanwhile } \\
\text { I've been pushing for Cali } \\
\text { Office to get the flashing } \\
\text { tools as well as it's a pretty } \\
\text { large office }\end{array}$ & $\begin{array}{l}\text { Actor733 is in contact with } \\
\text { one organization unit and } \\
\text { shares knowledge with } \\
\text { others in the message } \\
\text { thread. }\end{array}$ \\
\hline
\end{tabular}

\subsection{Knowledge Broker Exploring and Creating Knowledge}

Working in a globally dispersed organization poses challenges and opportunities for knowledge creation. Enterprise social media provides a useful platform for knowledge creation. Our third example shows how new knowledge is created in social media conversations. Table 3 shows conversation in the extracts in which exploring was the main activity of the knowledge broker. This particular example consists of a situation where product developers are resolving a problem that was affecting the whole organization. The employees were not able to use certain URL's in the internet, because there was a problem with the organization's proxy server and the access was denied to the client computers. To solve the problem, the developers shared knowledge that was used to fix the problem permanently and enabled employees to visit all websites from their work computers. In this case the Actor1250, was actively trying to find the solution and had knowledge of the possible solutions.

\section{Table 3. Knowledge broker exploring}

\begin{tabular}{ll}
\hline Data excerpt & Explanation \\
\hline Actor1250: so is there something & $\mathrm{KB}=$ Actor1250 \\
wrong in the http;//proxyconf/proxy.pac & $\begin{array}{l}\text { Actor1250 is } \\
\text { rigorously }\end{array}$ \\
$\begin{array}{l}\text { containing static configuration for } \\
\text { different domains as it does not go to }\end{array}$ & $\begin{array}{l}\text { seeking for a } \\
\text { proxy? (Enterprise wide proxy policy }\end{array}$ \\
\hline
\end{tabular}




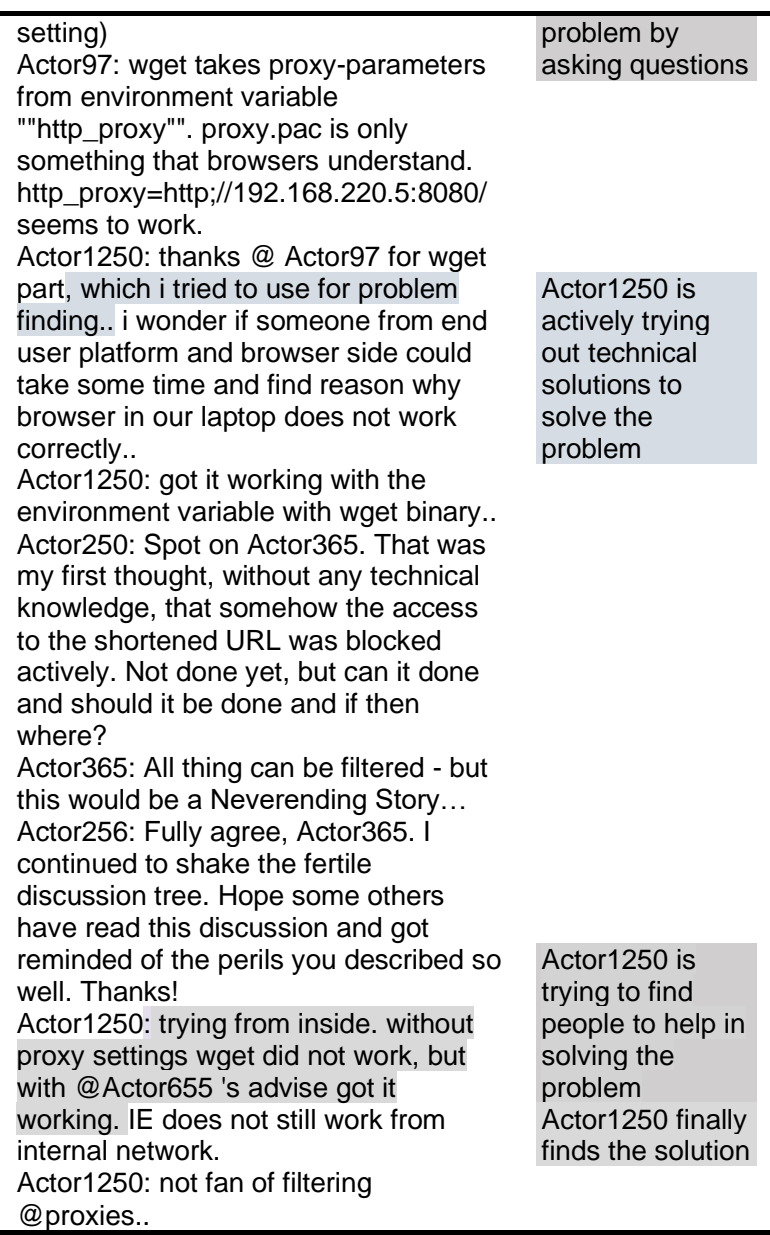

\subsection{Knowledge Broker Interacting}

One of the main activities of knowledge brokers in the ESM was group interaction. Knowledge brokers facilitated conversations by asking questions, proposing other actors to become discussants and making suggestions on how to proceed with the task at hand. By interacting, the knowledge broker enhanced collaboration in the network. Table 4 shows an extract of a conversation where the knowledge broker acts as facilitator of the interaction, a conversation where the knowledge broker is active in interaction. A wider extract of this conversation is presented in the Appendix A.

Table 4. Knowledge broker interacting

\begin{tabular}{ll}
\hline Data excerpt & Explanation \\
\hline Actor5844: This is a bug, & $\mathrm{KB}=$ Actor5844 \\
currently being worked on by & Actor5844 enters the \\
the SDK team, ... & conversation without being \\
\hline
\end{tabular}

Actor5844: You can have a look at http;//..., vote for the bug and follow it. I would have expected that fixing it...

Actor5844: You mean the QML web browser, right? It seems to complain about the UIWebKit 1.0 and not being able to find/load it. I'm rather sure I have it installed but it seems I don't, so I'll install it again ...

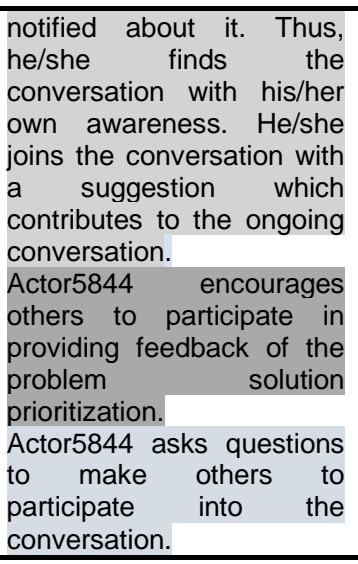

\section{Discussion}

Knowledge brokering is important as it improves collaboration and knowledge sharing. Ever-increasing use of ESM in organizations provides knowledge brokers a platform to operate. It also provides researcher tools to investigate knowledge brokering in more detail. Being able to identify knowledge brokers based on their messages in an ESM gives possibilities to learn about knowledge brokering and helps organizations improve knowledge sharing and collaboration further by using knowledge brokers as mediators. This paper contributes to a larger body of literature on knowledge brokering $[14,32,38]$ and knowledge creation [16, 35] by taking a communicative perspective on the strategic use of knowledge brokering.

In this study we investigated how the organization's members used social media to communicate and collaborate. We found empirical evidence that a good number of prominent members adopted the internal social media as their communication platform and used it for actual work purposes. Our specific interest is on knowledge brokers - those knowledge workers who used social media widely to create, disseminate and share organizational knowledge. The importance of knowledge brokers has been recognized in prior studies in management and science [34, 38]. Our research helps develop a better and more nuanced understanding of how the communicative actions of organizational members in a collaborative network may help in developing effective practices of knowledge brokering. Additionally, when knowledge brokers can be identified from the network according to their message content, the organization may better learn to utilize the capabilities of knowledge brokers in knowledge sharing and collaboration. For knowledge to be useful in collaboration, it needs to be shared with the appropriate individuals, and these individuals can benefit from knowing who knows what and who are the most effective knowledge brokers. This is difficult to do with 
large networks with a fair number of structural holes. A structural hole is an actor in a network connected to other actors that are not connected with each other [7]. In such cases, knowledge brokers are uniquely positioned to disseminate knowledge, who may be unreachable otherwise.

In contrast to structural holes, we posit that perhaps knowledge brokering is less effective in networks with high transitivity-i.e., where members are connected to members who are also connected with each other. In our research, knowledge brokers act as active liaisons who link people and groups, create new knowledge and collaborate with a wide group of employees. The study clarifies and illustrates through examples what knowledge brokering can mean in social media environment.

The extant literature has recognized the importance of knowledge brokering for intra-organizational collaboration. However, most of the earlier research in this area has been conceptual, and most empirical studies are based on interviews and surveys. Empirical studies which provide the actual message contents of knowledge brokers are needed to better understand this phenomenon. Our study contributes to that end. Our quantitative analysis shows how social media activity varies between the users. Most people do not become very active in social media, but some do, and these individuals can have a major influence on how the new media becomes a routinized part of everyday working in an organization and provides value for its users. Our research also elaborated on the communicative actions used by the knowledge brokers, which we characterized as connecting, exploring and interacting, and provided examples of what they refer to in enterprise social media conversations.

This study is not without limitations. Our main assumption has been that knowledge brokers are active social media actors. It may very well be that there also exist more subtle forms of knowledge brokering. Our analysis pinpointed users who could be categorized as 'super brokers': persons who are very active in social media and very widely connected. The analysis of their communication, however, gives us a good reference point for future analyses. The knowledge brokering communicative actions can be used as a guideline for wider analysis of the enterprise social media communication. In addition, our analysis only reveals the positive influencing elements of knowledge brokering. Our analysis does not look into the full communication profiles of the recognized knowledge brokers but is confined to the shared practices of the recognized knowledge brokers. Therefore, more detailed analysis of the knowledge brokering communication might reveal differences in knowledge brokers' communicative actions and strategies.
Moreover, it needs to be recognized that despite the increasing importance and interest in social media, not all communication and collaboration in an organizational environment happens through the ESM, but may also occur via email, telephone and face to face. Our research primarily reveals the knowledge brokering practices in social media environments.

Overall, our study shows that knowledge brokers do exist and play an important role in disseminating knowledge efficiently, particularly in networks characterized by many structural holes. These results can be used as a benchmark by organizations looking to adapt and boost the use of social media tools for effective collaboration. Knowledge brokers act as mediators and translators connecting people and ideas in the organization. This is beneficial to organizations by expediting problem solving processes and making sharing of knowledge more robust. The recognition of the importance of knowledge brokers may help organizations facilitate the emergence of such individuals, promote knowledge brokering action in general and in particular. Moreover, the idea of brokering may help employees better utilize the new technological systems. Further, when the communicative actions of the knowledge brokers are defined, organizations can use these as basis for training selected employees to act as knowledge brokers.

\section{Conclusion}

The purpose of this study was to identify knowledge brokers and brokering actions by observing enterprise social media activity of the users and the communicative actions of the active knowledge brokers. In the first stage of the analysis the active knowledge brokers were identified. The active knowledge brokers were assumed to be those who post the most opening and commenting posts. Thus, activity in the internal social media was assumed to correlate with knowledge brokering. The second stage of the analysis looked at the data by social network analysis and found that the most active actors seemed to be also the most central in the network. In the third stage of our research we conducted qualitative analysis. The conversations of the seven most active knowledge brokers were analyzed and three common communicative actions: connecting, exploring and interacting were discovered. First, knowledge brokers connect people and information. They communicate with several communities of practices connecting different departments and organizational levels. Knowledge brokers 'bridge' people and knowledge. Second, they explore and try to find solutions to problems and questions. Here knowledge brokering activity refers to a) questions asked and b) solutions offered and tried. Third, knowledge brokers interact 
actively in conversations and thus improve collaboration in the organization. Finally, all these actions of knowledge brokers enhance knowledge sharing and creation in the enterprise social media.

As final conclusion we wish to emphasize how in our data knowledge brokering was closely and directly related to the everyday operations of the enterprise social media users. The themes, problems and settings discussed in the enterprise social media were such that they had practical relevance to their users. These topics might have been tackled also on other arenas, like during the accidental meeting at the water cooler or through a phone call to a colleague. Yet, in our case organization, these discussion topics are more and more discussed in virtual environments, thus in an ESM.

\section{References}

[1] Ahuja, Manju K and Carley, Kathleen M. (1999), "Network structure in virtual organizations", Organization Science 10(6): 741-757.

[2] Alavi, Maryam and Leidner, Dorothy E. (2001), "Review: Knowledge Management and Knowledge Management Systems: Conceptual Foundations and Research Issues", MIS Quarterly 25(1): 107-136.

[3] Ardichvili, Alexandre (2008), "Learning and Knowledge Sharing in Virtual Communities of Practice: Motivators, Barriers, and Enablers", Advances in Developing Human Resources 10(4): 541-554.

[4] Borgatti, S.P., M.G. Everett, J.C. Johnson. Analyzing Social Networks. Sage, Los Angeles.

[5] Blackler, Frank (1995), "Knowledge, Knowledge Work and Organizations: An Overview and Interpretation", Organization Studies 16(6): 1021-1046.

[6] Brown, John Seely; Collins, Allan; Duguid, Paul (1989), "Situated Cognition and the Culture of Learning", Educational Researcher 18(1): 32-42.

[7] Burt, R. S. (2004). "Structural Holes and Good Ideas." American Journal of Sociology 110: 249-399.

[8] Carlile, P. R. (2002). A pragmatic view of knowledge and boundaries: Boundary objects in new product development. Organization science, 13(4), 442-455.

[9] Chia, R. (2003), "From Knowledge-Creation to the Perfecting of Action: Tao, Basho and Pure Experience as the Ultimate Ground of Knowing", Human Relations 56(8): 953 981.

[10] Cillo, Paola (2005), "Fostering Market Knowledge Use in Innovation: The Role of Internal Broker", European Management Journal 23(4):404-412.
[11] Creswell, J. W. (2013), Research design: Qualitative, quantitative, and mixed methods approaches. Sage publications.

[12] Davenport, T. H. (1996), "Some principles of knowledge management", Strategy \& Business, 1(2), 34-40.

[13] Dennis, A.R., Fuller, R.M., Valacich J.S. (2008) Media, Tasks, and Communication Processes: A Theory of Media Synchronicity. MIS Quarterly 32(3) 575-600.

[14] Dobbins, Maureen; Robeson, Paula; Ciliska, Donna; Hanna, Steve; Cameron, Roy; O'Mara, Linda; DeCorby, Kara and Mercer Shawna (2009), "A description of a knowledge broker role implemented as part of a randomized controlled trial evaluating three knowledge translation strategies", Implementation Science 4:23

[15] Ellison, N. B., J. L. Gibbs, and M. S. Weber (2014), "The Use of Enterprise Social Network Sites for Knowledge Sharing in Distributed Organizations: The Role of Organizational Affordances." American Behavioral Scientist, July: $1-21$.

[16] Engeström, Y. (2008). From teams to knots: Activitytheoretical studies of collaboration and learning at work. Cambridge University Press.

[17] Espinosa, J. A., N. Nan, et al. (2015). "Temporal Distance, Communication Patterns, and Task Performance in Teams." Journal of Management Information Systems 32(1): $151-191$.

[18] Faraj, S. and L. Sproull (2000). "Coordinating Expertise in Software Development Teams." Management Science 46(12): 1554-1568.

[19] Freeman, L.C. (1978) Centrality in Social Networks Conceptual Clarification. Social Networks 1(3) 215-239.

[20] Habermas, J. (2015). The Theory of Communicative Action: Lifeworld and Systems, a Critique of Functionalist Reason (Vol. 2). John Wiley \& Sons.

[21] Hargadon, Andrew, and Robert I. Sutton (1997), "Technology Brokering and Innovation in a Product Development Firm", Administrative Science Quarterly 42(4):716-49.

[22] Järvenpää, Sirkka and Leidner, Dorothy (1999), "Communication and Trust in Global Virtual Teams", Organization Science 10(6): 791-815.

[23] Leistner, Frank (2010), Mastering Organizational Knowledge Flow: How to Make Knowledge Sharing Work, John Wiley \& Sons, New Jersey.

[24] Leonardi, P. M., Huysman, M., \& Steinfield, C. (2013), "Enterprise social media: Definition, history, and prospects for the study of social technologies in organizations", Journal of Computer-Mediated Communication, 19(1), 1-19. 
[25] Leonardi, P. M. (2015), Ambient awareness and knowledge acquisition: using social media to learn 'who knows what'and 'who knows whom'.

[26] Lewis, K., D. Lange, et al. (2005). "Transactive Memory Systems, Learning and Learning Transfer." Organization Science 16(6): 581-598.

[27] Loew, Robert, Udo Bleimann, and Paul Walsh (2004), "Knowledge Broker Network Based on Communication between Humans", Campus-Wide Information Systems 21(5):185-90.

[28] Lomas, J. (2007), "The in-between world of knowledge brokering”, Bmj, 334(7585), 129-132.

[29] Long, J. C., Cunningham, F. C., \& Braithwaite, J. (2013). Bridges, brokers and boundary spanners in collaborative networks: a systematic review. BMC health services research, 13(1), 158.

[30] Martins, Carla Sofia and Patrício, Lia (2013), "Understanding participation in company social networks", Journal of Service Management 24(5): 567-587.

[31] Mell, J. N., D. van Knippenberg, et al. (2014). "The Catalyst Effect: The Impact of Transactive Memory System Structure on Team Performance." Academy of Management Journal 57(4): 1154-1173.

[32] Meyer, M. (2010), "The Rise of the Knowledge Broker", Science Communication 32(1):118-27.

[33] Molina-Azorin, J. F., Bergh, D. D., Corley, K. G., \& Ketchen Jr, D. J. (2017). Mixed methods in the organizational sciences: Taking stock and moving forward.

[34] Mäkelä, K., Barner-Rasmussen, W., Ehrnrooth, M., \& Koveshnikov, A. (2019). Potential and recognized boundary spanners in multinational corporations. Journal of World Business.

[35] Nonaka, Ikujiro, and von Krogh, Georg (2009), "Perspective--Tacit Knowledge and Knowledge Conversion: Controversy and Advancement in Organizational Knowledge Creation Theory", Organization Science 20(3):635-52.

[36] Nonaka, I. (1991), "The knowledge-creating company", Harvard Business Review, 69(6), 96-104.

[37] Obstfeld, D. (2005). Social networks, the tertius iungens orientation, and involvement in innovation. Administrative Science Quarterly, 50(1), 100-130.

[38] Olejniczak, K., Raimondo, E., \& Kupiec, T. (2016), "Evaluation units as knowledge brokers: Testing and calibrating an innovative framework", Evaluation, 22(2), 168189.

[39] Otte, E., \& Rousseau, R. (2002), "Social network analysis: a powerful strategy, also for the information sciences", Journal of Information Science, 28(6), 441-453.

[40] Powell, Anne; Piccoli, Gabriele and Ives, Blake (2004), "Virtual teams: a review of current literature and directions for future research." The data base for Advances in Information Systems 35(1).

[41] Pawlowski, Suzanne D. and Robey, Daniel (2004), "Bridging User Organizations: Knowledge Brokering and the Work of Information Technology Professionals" MIS Quarterly 28(4): 645-672.

[42] Ren, Y., K. M. Carley, et al. (2006). "The Contingent Effects of Transactive Memory: When is it More Beneficial to Know What Others Know?" Management Science 52(5): 671682.

[43] Stasser, G., Stewart, D. D., \& Wittenbaum, G. M. (1995), "Expert roles and information exchange during discussion: The importance of knowing who knows what", Journal of Experimental Social Psychology, 31(3), 244-265.

[44] Tushman, M. L., \& Scanlan, T. J. (1981). Boundary spanning individuals: Their role in information transfer and their antecedents. Academy of management journal, 24(2), 289-305.

[45] Treem, J. W., \& Leonardi, P. M. (2013). Social media use in organizations: Exploring the affordances of visibility, editability, persistence, and association. Annals of the International Communication Association, 36(1), 143-189.

[46] Verona, G.; Prandelli, Emanuela and Sawhney, Mohanbir (2006), "Innovation and Virtual Environments: Towards Virtual Knowledge Brokers." Organization Studies, 27(6):765-88.

[47] Waring, J., Currie, G., Crompton, A., \& Bishop, S. (2013). An exploratory study of knowledge brokering in hospital settings: Facilitating knowledge sharing and learning for patient safety? Social Science \& Medicine, 98, 79-86.

[48] Wenger, Etienne (1998), Communities of Practice: Learning, Meaning, and Identity, Cambridge University Press, UK.

[49] Young, A. M., \& Hinesly, M. D. (2014), "Social Media Use to Enhance Internal Communication Course Design for Business Students", Business and Professional Communication Quarterly, 2329490614544735. 


\section{APPENDIX A}

The full conversations in Table 4. The extract of a conversation where knowledge broker acts to enhance the interaction.

Actor2548: can't seem to remote-compile any of the examples for an $\mathrm{s}^{\wedge} 3$ target using Ulcreator on my mac...

Actor3541: Get outside proxy and try again

Actor2548: @Actor3541 i'm not behind the intranet proxy

Actor5844: Then describe the problem in a bit more detail. Does the authentication with ...com fail?

Is the project being sent to the server? What are you getting back?

Actor2548: @Actor5844 OK, point taken, I didn't really include enough info for you guys to help me. Here is what I'm trying: 1. open the "easing curves" example in UICreator 2. click "Projects" 3. change the remote compiler target to "CaseCompany PlatformY^3 v0.9" with UI version "UI4.6.3 with Mobility 1.0.2" 4. click Build 5. after a little while, I get three identical error messages" "/Developer/...error: UIDeclarative/QDeclarativeView: No such file or directory" I'm outside the firewall and have signed into the remote compiler backend with my Forum CaseCompany credentials, and the remote compiler does seem to want to compile the source. It's just that it fails.

Actor5844: The compiler does give you the correct output, it is just that as usual a bit of context info is needed to understand it. You are building a Declarative UI example (aka QML, aka UI Quick) but that technology is only available since UI 4.7 so your current choice (UI 4.6.3) is not suitable. There is another example, under c:l..।, and you should be able to compile that one with your current compiler config, since it does not need QML.

Actor3541: This is not a rare mishap, people botch with the UI version selection all the time. We are changing it so that UI 4.6 .3 is NOT the default, as it's not something we recommend most people to use anyway (people should be using UI Quick, not QWidgets or QGV).

Actor2548: Doh. That makes sense. I managed to build the QML easing curves by switching the UI Version to "UI 4.7.0 (Experimental) with Mobility 1.1.0". Rolls right off the tongue... ;-) That gets me a nice .Examplex file. However, I can't actually install it on the device, because the 4.7.0 UI libs are not installed. What next? The "Smart Installer" option is greyed out in UICreator. Is there a Examplex file downloadable with these libraries? (I found http...com/.html but that assumes Windows, and I'm on a Mac.) Thanks for all the help so far!

Actor5844: This is a bug, currently being worked on by the SDK team, which will have to put the UI for PlatformY Example files in the SDK package. Your only change now is to ... call a friend, and ask him/her to give you the needed EXAMPLE files ;)

Actor2548: Ah. I guess I can feel good for not missing something super-obvious at least ;-) It'd sure be swell if that addition to the SDK would be made available soon, since it's kinda essential... And - truth in advertising and all that - someone should update the public web site and tell people that these bits of the SDK are not there yet. I at least read the public announcement and said to myself "finally! time to play with qml" (Oh, and since we're all friends here on socialcast, I wouldn't mind at all if someone sent me those libs...)

Actor5844: You can have a look at http;//..., vote for the bug and follow it. I would have expected that fixing it takes 2 minutes (including testing and deployment) but it seems to be a bit more to it than that. Then again, a problem for which I was expecting long discussions about how and when was fixed in 2 minutes ;)

Actor5844: @Actor2548 You shoud be able to find the EXAMPLE files in my sharepoit site

Actor2548: @Actor5844 Voted for the bug \& got the libs - thanks!

Actor2548: @Actor5844 With UI_all.Example and Ulwebkit_2_1.Example installed (thanks again for those), I was able to install and run the easingcurves example on an $\mathrm{S}^{\wedge} 3$ device. So far, so good. Next, I tried the webbrowser example. It also builds and installs OK, but when I run it, all I get is a blank screen on the device. What I actually want to try and build eventually is http;//wiki...), because I want to try and port http;//... First as a UIWRT app, and then eventually with a native QLM UI. But the AABBproject project doesn't even compile...

Actor855: @Actor2548 I've played a bit with AABBproject UI port as well, and didn't manage to build it as-is either. I needed to comment out lot of the extension stuff (which I didn't need) in order to build it. Probably something relatively easy to fix if you know what you're doing - I didn't need all of those extensions so didn't put that much. 